\title{
El derecho a la igualdad y la prohibición de la discriminación en el caso de los hijos nacidos fuera del matrimonio
}

\author{
The right of equality and the prohibition of \\ discrimination in cases of children born out of wedlock
}

\author{
Ruperto Pinochet Olave ${ }^{1}$ \\ Universidad de Talca \\ rpinoche@utalca.cl \\ Gonzalo Aguilar Cavallo ${ }^{2}$ \\ Universidad de Talca \\ email
}

Resumen: Las sentencias que rechazan los recursos de protección mencionados, y que permiten discriminar entre hijos matrimoniales y no matrimoniales con un impacto en la sucesión hereditaria, hacen una aplicación

1 Profesor de Derecho civil y Director del Departamento de Derecho Privado y Ciencias del Derecho de la Universidad de Talca. Doctor en Derecho civil por la Universidad de Barcelona. Socio en Pinochet \& Concha Abogados, www.bonafides.cl, Talca. Correo electrónico: rpinoche@ utalca.cl.

2 Abogado (Chile), Doctor en Derecho (España), Magister en Relaciones Internacionales (España), Master en Derechos Humanos y Derecho Humanitario (Francia). Postdoctorado en el Max Planck Institute for Comparative Public Law and International Law (Heidelberg, Alemania). Profesor de Derecho Constitucional, Internacional, Ambiental y Derechos Humanos, Centro de Estudios Constitucionales de Chile, Universidad de Talca (Santiago, Chile). Subdirector del Centro de Estudios Constitucionales de Chile (Santiago, Chile). 
erróneamente restrictiva de los derechos fundamentales reconocidos en la Constitución y en los tratados internacionales ratificados por Chile y vigentes.

Palabras clave: Principio de igualdad, prohibición de la discriminación, derechos fundamentales, hijos matrimoniales, Convención Americana sobre Derechos Humanos.

Abstract: The sentences that reject the aforementioned actions of protections and, which allow discrimination between matrimonial and non-matrimonial children with an impact on inheritance, make a wrongly restrictive application of the fundamental rights recognized in the Constitution and in international treaties ratified by Chile and in force.

Keywords: Equality principle, prohibition of discrimination, fundamental rights, children born inside marriage, Inter-American Convention on Human Rights.

\section{Introducción}

En los últimos años ha venido produciéndose un serio problema de interpretación de normas de rango constitucional, en relación a la exégesis errónea que a nuestro juicio ha hecho el Registro Civil, así como una línea jurisprudencial nacional que, aunque minoritaria en el año 2019, debiera encontrarse, por las razones que se dirán, completamente uniformada.

Según se explicará con mayor detenimiento más adelante, la jurisprudencia minoritaria que referimos hace prevalecer la Ley 10.271 de 1952, por sobre el principio de rango constitucional de igualdad entre los hijos, excluyéndose de la calidad de hijos naturales y, en consecuencia, desconociendo la calidad de herederos, a hijos cuya filiación se encontraba, por nacimiento, determinada respecto de su padre o madre, pero a cuyo respecto no se habían cumplido las formalidades que, en esa época, exigían los artículos 270 y 271 del Código Civil.

Para dar mayor actualidad a este comentario, únicamente hemos procedido a revisar sentencias correspondientes al año 2019. Podemos agrupar estas sentencias entre aquellas que acogen la acción constitu- 
cional, por unanimidad de sus integrantes, aquellas que acogen la acción constitucional, pero con votos disidentes, o bien, aquellas que rechazan la acción constitucional.

Entre las sentencias que acogen la acción constitucional, por unanimidad de sus integrantes, y que corresponde a la doctrina que estimamos correcta, se encuentran las siguientes sentencias:; Corte Suprema, Rol 215-2019, 03 de julio de 2019; Corte Suprema, Rol 12101-2019, de 25 de septiembre de 2019; Corte Suprema, Rol 21326-2019, de 26 de septiembre de 2019; Corte de Apelaciones de San Miguel, Rol 204-2019, de 4 de febrero de 2019; Corte de Apelaciones de Concepción, Rol 2359-2019, de 11 de marzo de 2019; Corte de Apelaciones de Arica, Rol 128-2019, de 13 de marzo de 2019; Corte de Apelaciones de San Miguel, Rol 6512019, de 15 de marzo de 2019; Corte de Apelaciones de Iquique, Rol 106-2019, de 17 de abril de 2019; Corte de Apelaciones de Santiago, Rol 3391-2019, de 29 de abril de 2019; Corte de Apelaciones de Santiago, Rol 10898-2019, de 24 de mayo de 2019; Corte de Apelaciones de Puerto Montt, Rol 925-2019, de 5 de junio de 2019; Corte de Apelaciones de Santiago, Rol 1049-2019, de 16 de junio de 2019; Corte de Apelaciones de Concepción, Rol 9516-2019, de 20 junio de 2019; Corte de Apelaciones de Chillán, Rol 813-2019, de 17 de julio de 2019.

En segundo lugar, las sentencias que acogen la acción constitucional, pero con votos disidentes, son: Corte Suprema, Rol 12325-2019, de 21 de agosto de $2019^{3}$ y Corte Suprema, Rol 14875-2019, de 1 de octubre de $2019^{4}$, en las que existen, en cada caso, dos votos disidentes que dan cuenta de la línea minoritaria a que hemos aludido. Asimismo, se puede mencionar la sentencia de la Corte de Apelaciones de Santiago, Rol 27876-2019, de 1 de agosto de 2019, no obstante, acoger, hubo un voto disidente 5 .

Por último, entre las sentencias que rechazan los recursos de protección interpuestos encontramos la de la Corte Suprema, Rol 61-2019, de

3 Votos en contra de los Ministros señora Sandoval y Señor Aránguiz.

4 Votos en contra de los abogados integrantes Gómez y Pallavicini.

5 Voto en contra de la Ministra Kittstainer. 
10 de abril de 20196; Corte de Apelaciones de Talca, Rol 599-2019, de 9 de abril de 2019 y de la Corte de Apelaciones de Valdivia, Rol 1490-2019, de 12 de julio de 2019.

\title{
2. La Ley 10.271 de 1952 y los problemas de interpretación que hoy provoca
}

\author{
En 1952, a través de la ley $\mathrm{N}^{\circ} 10.271$, se reconoció, por primera vez, \\ derechos hereditarios a los hijos no matrimoniales, incorporando al Códi- \\ go Civil los artículos $270^{7}$ y $271^{8}$. Además, debe advertirse que antes de \\ la entrada en vigencia de la ley $\mathrm{N}^{\circ} 19.585$, de 1998 , el reconocimiento vo-
}

6 Voto en contra del Ministro Señor Muñoz, quien estuvo por acoger la acción de protección.

7 Artículo 270. Los hijos ilegítimos tendrán la calidad de hijos naturales del padre o madre que los haya reconocido, o cuya paternidad o maternidad haya sido establecida en conformidad a las reglas del presente Título.

8 Artículo 271. Son hijos naturales:

1. Los que el padre, la madre o ambos hubieren reconocido como hijo suyo mediante una declaración formulada con ese determinado objeto en escritura pública, en la inscripción de nacimiento del hijo o en acto testamentario.

Con todo, el hecho de consignarse el nombre del padre o de la madre, a petición de ellos, en la inscripción del nacimiento, es suficiente reconocimiento de filiación natural.

El reconocimiento por acto entre vivos señalado en este número, podrá efectuarse por medio de mandatario constituido por escritura pública y especialmente facultado con este objeto.

2. Aquellos que hubieren obtenido el reconocimiento de la paternidad o maternidad natural por sentencia judicial.

La acción del presunto hijo a que se refiere este número deberá necesariamente fundarse en instrumento público o privado emanado del supuesto padre o madre del cual se desprenda una confesión manifiesta de paternidad o maternidad. El referido instrumento deberá acompañarse a la demanda y sin este requisito no se dará curso a ésta.

3. Los que hubieren poseído notoriamente, a lo menos durante quince años consecutivos, la calidad de hijo respecto de determinada persona.

La posesión de dicha calidad consiste en que su padre o madre le haya tratado como hijo, proveyendo a su educación y establecimiento de un modo competente y presentándolo en ese carácter a sus deudos y amigos, y que éstos y el vecindario de su domicilio, en general, le hayan reputado y reconocido como tal.

La posesión notoria deberá probarse por un conjunto de testimonios fidedignos, que la establezcan de un modo irrefragable. La prueba de testigos no bastará por sí sola para acreditarla.

4. Los que hubieren obtenido declaración de maternidad fundada en la circunstancia precisa de haberse establecido, con testimonios fidedignos, el hecho del parto y la identidad del hijo, y

5. Aquellos que hayan sido reconocidos por el supuesto padre, cuando, citado éste por el hijo a la presencia judicial, confesare la paternidad bajo juramento. Nadie podrá ejercer este derecho más de una vez con relación a la misma persona. 
luntario se consideraba una facultad del padre y no un derecho del hijo 9 .

Como se explica en el Boletín N¹2104-07, de la Cámara de Diputados, que Modifica la ley $N^{\circ} 19.585$ en materia de determinación de filiación de los hijos naturales que hayan sido reconocidos mediante declaración ante el Servicio de Registro Civil, con anterioridad a su entrada en vigencia, hasta antes de la promulgación de la ley 10.271 del año 1952, el reconocimiento de un hijo no matrimonial (natural a la época) se debía hacer al momento de inscribir el nacimiento, o bien, en un acto posterior, mediante manifestaciones expresas de voluntad contenidas en una escritura pública o en un acto testamentario, el cual, además, debía subinscribirse al margen de la partida de nacimiento, adicionalmente, ese reconocimiento debía ser aceptado por el inscrito (el hijo reconocido), debiendo subinscribirse la respectiva escritura de aceptación.

De este modo, si una persona concurría directamente al Registro Civil a reconocer a un hijo, se dejaba constancia en la partida de su nombre como padre o madre, siendo esto insuficiente para tener por determinada la paternidad, por parte del progenitor que reconocía, le faltaba, adicionalmente, de acuerdo a la ley vigente, escritura pública de reconocimiento $\mathrm{y}$, de parte del reconocido, escritura pública de aceptación. A pesar de aquello, si faltaban estos trámites adicionales, igual quedaba registrado el nombre del padre o madre que había reconocido a su hijo en esa calidad. Así también se consignaba en sus certificados de nacimiento ${ }^{10}$.

De este modo, visto desde la actualidad, se da la paradoja de que, si bien, en muchos casos no cabe duda de que un padre o una madre lo son de un hijo determinado, lo que hoy entenderíamos por determinación de la filiación, en esa época si no se habían cumplido las gravosas formalidades antes señaladas, el hijo no obtenía la calidad de "natural" y, por consiguiente, no adquiría derechos sucesorios.

9 ROdRÍGuez (2013).

10 En el mismo Boletín se señala "Como se ve, había un sinnúmero de actos formales que dificultaban el término del proceso. Si eso lo llevamos al Chile de la época, donde la mayor parte de los nacimientos de hijos naturales se daba en hogares más modesto, donde el acceso a todas estas solemnidades era especialmente dificultoso, no es extraño que pocas veces haya podido cumplir con las solemnidades requeridas y contar con una filiación legalmente determinada". 
En el mismo Boletín se explica "Aunque la ley 10.271 aligeró los trámites, permitiendo el reconocimiento mediante el acto voluntario expresado ante el Servicio de Registro Civil e Identificación, las normas transitorias dictadas con ella fueron insuficientes. A pesar de que los certificados de nacimiento de quienes fueron reconocidos únicamente por un acto voluntario ante un oficial de Servicio de Registro Civil e Identificación figuran con el nombre del padre o madre que los reconoció, estos no han sido considerados como suficientes por parte del Estado para reconocer la filiación, y, por lo tanto, el estado civil de hijos, y así se les ha negado de forma sistemática los derechos que emanan de la filiación y del estado civil de hijo, especialmente en lo referido a derechos hereditarios".

Es por eso que en 1998, según se manifiesta, se estimaba que dicha interpretación, la de no reconocer derechos a dichos hijos, no había sido arbitraria ni contraria a derecho, sino que se trataba de la aplicación de una norma con defectos en su redacción, en donde el Servicio de Registro Civil e Identificación se había limitado a aplicar la norma transitoria de la ley 19.585, ya que el estado civil es consecuencia de la filiación, y si ésta no está "legalmente determinada", conforme a la ley vigente a la fecha del reconocimiento, no puede reconocérsele los derechos inherentes de hijo o de padre, según corresponda.

Ha sido en su calidad de persona mayores donde muchos de esos hijos se han dado cuenta que, a pesar de que el nombre de su padre o madre aparece en sus certificados de nacimiento, y que han vivido toda su vida como hijos, con la legítima convicción de que su filiación está legalmente determinada, el Estado chileno no les reconoce esa filiación. Y, esto ha ocurrido, especialmente, al momento de la tramitación de la posesión efectiva ante el Servicio de Registro Civil e Identificación, en donde se les niega la calidad de herederos abintestato. Así por ejemplo, lo explica el Registro Civil al informar en términos muy similares en todos los recursos citados que hasta antes de la entrada en vigencia de la Ley $\mathrm{N}^{\circ} 10.271$, el Código Civil establecía que el reconocimiento de hijos no matrimoniales se debía realizar al momento de inscribir el nacimiento o bien en un acto posterior, mediante manifestaciones expresas de voluntad contenidas en una escritura pública o en un acto testamentario, documentos que debían 
quedar subinscritos al margen de la inscripción de nacimiento, requiriéndose, además, que dicho reconocimiento fuera aceptado por parte del inscrito o su curador, si éste fuere menor de edad. Agrega que el artículo sexto transitorio de la Ley $N^{\circ} 10.271$ reguló expresamente la situación de aquellas personas inscritas con anterioridad a la entrada en vigencia de dicha ley y que no habían sido objeto de reconocimiento, otorgando el derecho a su titular para interponer la acción de reconocimiento forzado en el plazo de dos años contados desde la entrada en vigencia de la nueva ley. Luego, analiza la Ley $\mathrm{N}^{\circ} 19.585$, concluyendo que aquella no terminó con las distinciones entre hijos, sino que partiendo de la premisa que estado civil y filiación no son sinónimos únicamente otorgó a los denominados hijos legítimos, legitimados y naturales, los mismos derechos, constituyéndolos en hijos de filiación determinada, mientras que los ilegítimos solo pueden tener filiación indeterminada y, por consiguiente, no tienen los mismos derechos que los primeros. Afirma que en este caso la recurrente no tiene, respecto de su madre $X X X X X X$, la calidad de hija natural, sino que de simplemente ilegítima, vínculo que no importa filiación, de modo que la constancia del nombre de la madre en la partida de inscripción de nacimiento únicamente establece su estado civil, pero no constituye filiación. Por último, sostiene que la irretroactividad de las leyes es la regla general y la excepción la retroactividad, caso en el cual por su naturaleza las normas deben ser interpretadas en sentido restrictivo. Por lo expuesto, considera no haber incurrido en ningún acto ilegal o arbitrario, ya que la resolución de rechazo se fundamenta en los preceptos e instituciones legales a los cuales se ha hecho referencia.

Lo anterior nos parece una equivocada recepción del principio de igualdad de los hijos. La Ley 19.585, introdujo en el ordenamiento jurídico nacional varios principios en materia de filiación y, por tanto, en materia de estado civil, que derivaban, por lo demás, de obligaciones que había contraído el estado de Chile, en materia de Derechos fundamentales, así Ramos explica que "Los cambios que introduce la Ley $N^{\circ} 19.585$, tienen por objeto hacer realidad el claro mandato constitucional y además dar cumplimiento a diversos tratados ratificados por Chile, que el artículo $5^{\circ}$ de la Carta Fundamental obliga a respetar. Entre esos tratados merece 
citarse especialmente el llamado Pacto de San José de Costa Rica, que en su artículo $17 N^{\circ} 5$ proclama que "La ley debe reconocer iguales derechos tanto a los hijos nacidos fuera del matrimonio como a los nacidos dentro del mismo... Que el segundo principio consiste "en el trato igualitario a todos los hijos. La Ley $N^{\circ} 19.585$ iguala los derechos de todos los hijos, con lo que no hace más que cumplir con el claro mandato de la Constitución Política de la República, que entre las bases de la institucionalidad establece: "Las personas nacen libres e iguales en dignidad y derechos" (art. $1^{\circ}$ inc. $1^{\circ}$ ), agregando en seguida que "es deber del Estado asegurar el derecho de las personas a participar con igualdad de oportunidades en la vida nacional"11.

Que, adicionalmente al principio antes enunciado y a los tratados internacionales ratificados por Chile, estimamos que hoy en día debe tenerse en cuenta, para la aplicación e interpretación de cualquier ley que afecte a personas adultas mayores, la Convención Interamericana sobre la Protección de los Derechos Humanos de las personas Mayores ${ }^{12}$, la que en su artículo 3, indica los principios generales aplicables a la protección de los derechos humanos de las personas mayores, a saber: a) La promoción y defensa de los derechos humanos y libertades fundamentales de la persona mayor. b) La valorización de la persona mayor, su papel en la sociedad y contribución al desarrollo. c) La dignidad, independencia, protagonismo y autonomía de la persona mayor. d) La igualdad y no discriminación. e) La participación, integración e inclusión plena y efectiva en la sociedad. f) El bienestar y cuidado. g) La seguridad física, económica y social. h) La autorrealización. i) La equidad e igualdad de género y enfoque de curso de vida. j) La solidaridad y fortalecimiento de la protección familiar y comunitaria. k) El buen trato y la atención preferencial. I) El enfoque diferencial para el goce efectivo de los derechos de la persona mayor. $m$ ) El respeto y valorización de la diversidad cultural. $n$ ) La protec-

11 Ramos Pazos (2009), p. 401.

12 A través del decreto 162, del Ministerio de relaciones exteriores, se promulgó y publicó con fecha 7 de octubre 2017, la Convención Interamericana sobre la protección de los Derechos Humanos de las personas mayores. 
ción judicial efectiva. o) La responsabilidad del Estado y participación de la familia y de la comunidad en la integración activa, plena y productiva de la persona mayor dentro de la sociedad, así como en su cuidado y atención, de acuerdo con su legislación interna ${ }^{13}$.

A pesar de que interpretaciones de ese tipo se creían erradicadas con la adopción de los nuevos principios constitucionales de igualdad y prohibición de la discriminación en materia de filiación, como puede apreciarse, los resultados, al menos en parte, siguen siendo erráticos.

\section{Los principios constitucionales e internacionales de derechos humanos en juego}

\subsection{Los derechos humanos}

La igualdad es uno de los valores constitucionales expresamente reconocidos en la Constitución chilena el cual se articula, en una relación virtuosa, con el valor rector del orden constitucional, constituido por la dignidad humana. En efecto, el artículo $1^{\circ}$ de la Constitución señala en su inciso primero lo siguiente: "Las personas nacen libres e iguales en

13 En un sentido similar proponíamos en un trabajo anterior, la aplicación de la Convención interamericana sobre la protección de los derechos humanos de las personas mayores al Derecho de consumo nacional, pues -atendiendo a que nos encontramos en presencia de un instrumento de Derechos fundamentales- la Convención se incorpora al ordenamiento jurídico interno chileno por el denominado «bloque de constitucionalidad» que fluye de lo dispuesto por el inc. $2^{\circ}$ del artículo 5 de la Constitución política de la República de Chile:"El ejercicio de la soberanía reconoce como única limitación el respeto a los derechos esenciales que emanan de la naturaleza humana. Es deber de los órganos del Estado respetar y promover tales derechos, garantizados por esta Constitución, así como por los tratados internacionales ratificados por Chile y que se encuentren vigentes". Siendo la Convención un instrumento de Derechos humanos ratificado por Chile y que se encuentra vigente, con rango de norma constitucional, se impone por el principio de jerarquía a la Ley 19.496 de Protección de los consumidores y a sus normas complementarias, por lo que cada vez que exista una antinomia aparente entre nuestra Ley del Consumidor y la Convención, deberá prevalecer esta última por las razones ante dichas. Incluso, este propósito ha sido uno de los que se ha tenido en cuenta para promover la Convención al señalarse que "se impone el desafío de establecer mecanismos eficaces y específicos que garanticen la calidad de vida, el bienestar, la salud, seguridad social, así como todos los demás derechos civiles, políticos y económicos, sociales y culturales de las personas mayores, por lo que se hace necesario establecer estándares de protección más específicos que los actualmente existentes". SENAmA 2017, disponible en http:// www.senama.gob.cl/storage/docs/Ratificacion-Conv-Interamericana-Prot-Derechos-Pers-Mayores.pdf, [Fecha de consulta: 26 de julio de 2018]. (PINOCHET (2019), p. 67). 
dignidad y derechos". Las normas infraconstitucionales, tales como la ley 10.271 y la ley 19.585 , deben subordinarse en su aplicación a este valor constitucional, este es precisamente el mandato constitucional emanado del artículo 6 de la Constitución y recoge el principio de supremacía constitucional y el de aplicabilidad directa de la Constitución. Es más, el artículo $1^{\circ}$ inciso $4^{\circ}$ de la Constitución completa y complementa la afirmación del inciso $1^{\circ}$, indicando que "El Estado está al servicio de la persona humana y su finalidad es promover el bien común, para lo cual debe contribuir a crear las condiciones sociales que permitan a todos y a cada uno de los integrantes de la comunidad nacional su mayor realización espiritual y material posible, con pleno respeto a los derechos y garantías que esta Constitución establece".

Desde la perspectiva de los derechos, el artículo $19 \mathrm{~N}^{\circ} 2$ de la Constitución chilena consagra el derecho a la igualdad y la prohibición de la discriminación. El derecho a la igualdad y la prohibición de la discriminación son dos caras de la misma moneda. Se deprende del artículo $19 \mathrm{~N}^{\circ} 2$ que la Constitución sólo admite diferencias de trato en la medida que estas sean objetivas, razonables y proporcionadas. Estos criterios de decisión acerca de cuando estamos ante un acto discriminador, se ven complementados con las denominadas categorías prohibidas de discriminación y las categorías sospechosas, más el principio del deber de protección reforzada por parte del Estado de los grupos vulnerables. En los casos de marras, primero la ley, y luego, el juez, efectúan una diferencia de trato que no supera el test de la legitimidad de la distinción, tanto en cuanto la diferencia de trato en que se incurre, entre hijos matrimoniales e hijos no matrimoniales, es irracional y desproporcionada. De hecho, habría un grupo de hijos no matrimoniales, nacidos en un período determinado de tiempo que establecen las leyes, que no serían reconocidos como hijos a menos que se hubieran realizado las formalidades que hemos mencionado supra, vis-a-vis los hijos no matrimoniales nacidos después de ese período que sí serían considerados hijos, sin necesidad de cumplir dichas formalidades, y que, consecuentemente, sí tendrían acceso, por ejemplo, a la sucesión hereditaria de sus padres. ¿Tiene alguna justificación esta distinción que realiza el legislador y, en casos, el juez, a la luz del derecho 
a la igualdad y la prohibición de la discriminación? Estimamos que no.

Por otro lado, esta diferencia de trato entre un grupo de niños y otro, se refiere directamente a una categoría prohibida de discriminación. En efecto, el artículo 1.1. de la Convención Americana sobre Derechos Humanos señala expresamente que los Estados partes están obligados a respetar los derechos de todas las personas bajo su jurisdicción "sin discriminación alguna por motivos [...] nacimiento o cualquier otra condición social." Misma prohibición se encuentra en el artículo 2.1. del Pacto Internacional de Derechos Civiles y Políticos. Por tanto, el nacimiento no puede ser utilizado por el Estado como una justificación para realizar tratos diferenciados. Incluso más, la sola invocación de este criterio como causal de diferenciación debe hacer sospechar al juez que la medida diferenciadora, es discriminatoria. El hecho de que el motivo de discriminación se encuentre en el nacimiento del niño, niña y adolescente, pero los efectos de esta discriminación se concretan, por lo general, en personas mayores, genera que el Estado, a través de sus órganos, tengan un deber redoblado de cuidado y protección, ya que sus actos se refieren a grupos especialmente vulnerables. Cabe, en este sentido, recordar que el artículo $1^{\circ}$ inciso final de la Constitución señala que es deber del Estado proporcionar protección a la población y promover la integración armónica de todos los sectores de la Nación. A este respecto, el Tribunal Constitucional ha afirmado que "el artículo $1^{\circ}$ de la Carta Fundamental es de un profundo y rico contenido doctrinario, que refleja la filosofía que inspira nuestra Constitución y orienta al intérprete en su misión de declarar y explicar el verdadero sentido y alcance del resto de la preceptiva constitucional." 14

Igualmente, la diferencia de trato respecto de los hijos no matrimoniales, que la doctrina minoritaria intenta sostener en sus decisiones, vulnera el derecho a la identidad personal y al desarrollo de su personalidad. En efecto, la doctrina minoritaria les niega el carácter de hijos, por el sólo hecho que, en su momento, no se concretaron las formalidades requeridas para ser reconocidos como hijos naturales, todo ello, a pesar de que eran

14 Tribunal Constitucional, Rol N¹9-83,29 de octubre de 1983. Considerando $9^{\circ}$. 
reconocidos como hijos, por sus padres, en la inscripción de nacimiento.

A este respecto, el Tribunal Constitucional chileno ha afirmado que "el reconocimiento del derecho a la identidad personal en cuanto emanación de la dignidad humana- implica la posibilidad de que toda persona pueda ser ella misma y no otra, lo que se traduce en que tiene derecho a ser inscrita inmediatamente después de que nace, a tener un nombre desde dicho momento y, en la medida de lo posible, a conocer a sus padres y a ser cuidada por ellos. Si bien esta forma de entender el derecho a la identidad personal se deriva del artículo $7^{\circ}$ de la Convención sobre los Derechos del Niño, no cabe restringir su reconocimiento y protección a los menores de edad. Ello, porque el derecho a la identidad personal constituye un derecho personalísimo, inherente a toda persona, independientemente de su edad, sexo o condición social.

La estrecha vinculación entre el derecho a la identidad personal y la dignidad humana es innegable, pues la dignidad sólo se afirma cuando la persona goza de la seguridad de conocer su origen y, sobre esa base, puede aspirar al reconocimiento social que merece. Desde este punto de vista, el derecho a la identidad personal goza de un status similar al del derecho a la nacionalidad del que una persona no puede carecer.

Las consideraciones que preceden justifican, precisamente, incluir el derecho a la identidad personal entre aquellos derechos esenciales a la naturaleza humana a que alude el artículo $5^{\circ}$, inciso segundo, de la Constitución, y que se erigen como límite de la soberanía, debiendo los órganos del Estado respetarlos y promoverlos, ya sea que estén asegurados en la propia Carta Fundamental o en tratados internacionales ratificados por Chile y que se encuentren vigentes." 15

Consecuentemente, el derecho a la identidad personal y al libre desarrollo de la personalidad, constituyen, sin duda, atributos inherentes al ser humano. $Y$ en este sentido, el Tribunal Constitucional ha señalado que "lo que limita el ejercicio de la soberanía son aquellas facultades propias o inherentes a toda persona en cuanto tal, que no pueden ser desconocidas o atropelladas por el ejercicio concreto de la potestad soberana

15 Tribunal Constitucional, Rol N¹340.09, 29 de septiembre de 2009. Considerando $10^{\circ}$. 
del Estado que, de conformidad con la misma Carta Fundamental, está al servicio de la persona humana (artículo $1^{\circ}$, inciso tercero)." ${ }^{16}$

\subsection{Los principios de interpretación}

Desde el punto de vista de la interpretación, la doctrina minoritaria no utiliza los principios de interpretación pertinentes para solucionar una controversia de derechos fundamentales como la de los casos de marras. En efecto, uno de los principales argumentos esgrimidos por algunos jueces para rechazar la acción constitucional reside en razones legales no constitucionales y mucho menos constitucionales. Así, se sostiene que, de acuerdo con la ley de efecto retroactivo de las leyes, a los casos de marras, debe aplicarse la ley vigente al momento de la ocurrencia de los hechos, esto es, la ley 10.271 de 1952, a pesar de que el caso se presenta en el año 2019, por ejemplo. Frente a esto, cabe preguntarse ¿por qué el juez que conoce de una acción constitucional protectora de derechos fundamentales no aplica la Constitución y, por sobre todo, los derechos fundamentales, que es sobre lo que versa la acción constitucional de protección? A nuestro entender, esta acción constitucional de protección requiere que las Cortes defiendan la vigencia plena de los derechos humanos que se encuentran reconocidos directamente en la Constitución o bien, por la vía del artículo 5 inciso $2^{\circ}$ de la Constitución. En efecto, el juez, al hacer una interpretación de los derechos, no solo debe tomar en cuenta la ley formalmente relacionada con éste, sino también el sistema constitucional y de derechos dentro del cual se inscribe. ${ }^{17}$

En este sentido, el Tribunal Constitucional ha señalado claramente que "conviene recordar que uno de los acuerdos adoptados por los redactores de la reforma constitucional de 1989, fue la proposición de incorporar a la Constitución los derechos humanos contenidos en las normas internacionales que comprometieran a Chile. (Ello, porque) el artículo $5^{\circ}$ originario de la Constitución de 1980 colocaba los derechos esenciales

16 Tribunal Constitucional, Rol N¹563-09, 30 de agosto de 2011. Considerando $11^{\circ}$

17 Mutatis mutandis, Corte IDH: Caso de la Comunidad Indígena Yakye Axa. Sentencia 17 de junio de 2005. Serie C No. 125, par. 125. 
de la persona como una limitación a la soberanía. Congruente con ello, se propuso agregar una frase al artículo $5^{\circ}$, inciso segundo, de la Constitución, que expresara: Es deber de los órganos del Estado respetar y promover tales derechos, garantizados por esta Constitución y por las normas internacionales que comprometan a Chile. Por sugerencias del representante del gobierno de la época, se precisó la parte final de la frase indicando que los derechos incorporados serían los contenidos en los tratados internacionales ratificados por Chile y que se encuentren vigentes, redacción que, en definitiva, fue aprobada. ${ }^{18}$

Sobre el particular, este Tribunal ha afirmado que esta última expresión (que el ejercicio de la soberanía reconoce como limitación el respeto a los derechos esenciales que emanan de la naturaleza humana) significa que los hombres son titulares de derechos por ser tales, sin que sea menester que se aseguren constitucionalmente para que gocen de la protección constitucional. (Sentencia Rol No 226, considerando 25)."19

En materia de derechos humanos, es un principio generalmente aceptado que la interpretación de los derechos debe acompañar la evolución de los tiempos y que el juez debe interpretar los derechos de las personas a la luz de las condiciones de vida actuales a fin de optimizar el pleno disfrute de los derechos. ${ }^{20}$ Desde la perspectiva de los derechos humanos, el juez que resuelve la acción constitucional debiera aplicar este principio de interpretación evolutiva, y no subordinar el goce de derechos a normas legales pasadas, que permiten desvirtuar y vulnerar el goce efectivo de los derechos. Por ello, es preciso reiterar, este no es un caso de derecho de familia subordinado al derecho civil, sino más bien, es un caso de derechos fundamentales, sujeto a todas las reglas y principios protectores propios de este ámbito.

Además, las opiniones minoritarias no han aplicado el principio de in-

18 CUMPLIDo (1996), p. 256.

19 Tribunal Constitucional, Rol N¹563-09, 30 de agosto de 2011. Considerando $11^{\circ}$.

20 Corte IDH: Caso de las Masacres de Ituango vs. Colombia. Sentencia de 1 de julio de 2006. Serie C No. 148, par. 155; Vid. Corte Europea de Derechos Humanos en los Casos Tyrer v. Reino Unido de 25 de abril de 1978, Marckx v. Bélgica de 13 de junio de 1979, y Loizidou v. Turquía (Excepciones Preliminares) de 23 de marzo de 1995. 
terpretación conforme a la Constitución. Este es un principio de interpretación ampliamente aceptado por la doctrina constitucional, y pilar fundamental de un Estado democrático y constitucional de Derecho. Si la corriente jurisprudencial de minoría hubiera utilizado el principio de interpretación de la ley 10.271, 19.585 y de la ley de efecto retroactivo de las leyes conforme a la Constitución, su interpretación necesariamente tendría que haber privilegiado la protección de los derechos de los recurrentes. Pero incluso más. Si el Servicio de Registro Civil hubiera utilizado el principio de interpretación conforme al momento de su decisión sobre la posesión efectiva, debería haber aplicado preferentemente las normas sobre derechos contenidas en la Constituciones, mencionadas supra, y aquellas recogidas en los tratados internacionales ratificados por Chile y vigentes, tales como el artículo 17.5. de la Convención Americana sobre Derechos Humanos.

$\mathrm{Y}$, last but not least, los intérpretes de la posición que estimamos de minoría, en la acción constitucional referida, no han aplicado el principio de interpretación pro homine o favor persona. Aunque se entiende por lo hasta aquí dicho, en igual falta ha incurrido el Servicio de Registro Civil al dejar fuera de la posesión efectiva a estos hijos no matrimoniales que se encuentran en la situación descrita en la primera parte. Como hemos reiteradamente sostenido, el principio pro homine se define como "[...] un criterio hermenéutico que informa todo el derecho de los derechos humanos, en virtud del cual se debe acudir a la norma más amplia, o a la interpretación más extensiva, cuando se trata de reconocer derechos protegidos e, inversamente, a la norma o a la interpretación más restringida cuando se trata de establecer restricciones permanentes al ejercicio de los derechos o su suspensión extraordinaria. Este principio coincide con el rasgo fundamental del derecho de los derechos humanos, esto es, estar siempre a favor del hombre. Un aspecto que caracteriza el principio pro homine es que no importando dónde se encuentre la norma, ya sea de nivel legal, constitucional o internacional, prevalecerá la que otorgue mayor protección a los derechos del individuo, o bien la que sea menos 
dañosa o restrictiva de estos derechos." ${ }^{21}$ Tanto la posición doctrinaria minoritaria como las interpretaciones del Servicio de Registro Civil, que niegan la posesión efectiva por no constar la calidad de hijo natural según las formalidades exigidas en la época, no realizan una interpretación favor persona. Hacen todo lo contrario. Interpretan extensivamente una restricción al goce o disfrute de un derecho fundamental, a saber, el derecho a la igualdad, la prohibición de la discriminación, el derecho a la identidad personal y el derecho al libre desarrollo de la personalidad, disminuyendo al máximo la facultad del goce de estos derechos. Todo ello, a pesar de que el artículo 29 de la Convención Americana sobre Derechos Humanos, por intermedio del artículo 5 inciso $2^{\circ}$ de la Constitución, los obligaba a usar el principio de interpretación pro homine para resolver este caso.

\section{Conclusión}

A juicio de estos comentaristas las sentencias que rechazaron los recursos de protección enunciados, así como los votos de minoría emitidos en el mismo sentido, hacen una errónea aplicación restrictiva de las garantías constitucionales debiendo haberlas interpretado retroactivamente dando valor a los cambios legislativos en materia de filiación, que vinieron a igualar en derechos a los hijos naturales con los hijos matrimoniales, esto debido a que era indispensable establecer un estatuto igualitario para todos los hijos en concordancia con lo establecido en el artículo $1^{\circ}$ de la Constitución Política de la República, que señala que "las personas nacen libres e iguales en dignidad y derechos", por lo que la antigua legislación constituía y constituye, cuando se la aplica erradamente, un trato discriminatorio. La correcta aplicación de la teoría que vela por la no discriminación de los hijos fluye además de obligaciones contraídas por Chile al ratificar tratados internacionales en materia de derechos humanos, como la Convención Americana sobre Derechos Humanos o Pactó de San José de Costa Rica, la que en su artículo $17 \mathrm{~N}^{\circ} 5$ establece que

21 Aguilar (2016), pp. 13-59, especialmente, pp. 30-31. 
"La ley debe reconocer iguales derechos tanto a los hijos nacidos fuera de matrimonio como a los nacidos dentro del mismo", principio que se encuentra igualmente contenido en la Convención sobre los Derechos del niño.

\section{Bibliografía}

Aguilar Cavallo, Gonzalo (2016): "Principios de interpretación de los derechos fundamentales a la luz de la jurisprudencia chilena e internacional", en Boletín Mexicano de Derecho Comparado, nueva serie, (Año XLIX, núm. 146, mayo-agosto) 2016, pp. 13-59.

Cumplido Cereceda, Francisco (1996): "Alcances de la modificación al artículo $5^{\circ}$ de la Constitución Política chilena en relación a los tratados internacionales" en Revista Chilena de Derecho, (Vol. 23, Nos 2 y 3. Tomo I), pp. 255-258

PInochet Olave, Ruperto (2019): "El consumidor y la tercera edad: ¿Una tutela diferente?" en Ferrante, Alfredo, Venta y protección del consumidor. Una visión a través del caleidoscopio latinoamericano (Santiago, Thomson Reuters) pp. 63-89.

Ramos Pazos, René (2009): Derecho de familia (Santiago, Editorial Jurídica de Chile).

Rodríguez, María Sara (2013): "El reconocimiento de los derechos hereditarios de hijos no matrimoniales" en Mercurio Legal, 9 de mayo de 2013 [fecha de consulta: 14 de octubre de 2019]. [Disponible en: http:// www.elmercurio.com/Legal/Noticias/Analisis-Juridico/2013/05/09/ El-reconocimiento-de-los-derechos-hereditarios-de-hijos-no-matrimoniales.aspx, revisado 14 de octubre de 2019]

\section{Normas jurídicas citadas}

Código de Procedimiento Civil. Diario Oficial, 30 de agosto de 1902. Decreto 100 del Ministerio Secretaría General de la Presidencia que Fija el Texto Refundido, Coordinado y Sistematizado de la Constitución Política de la República de Chile. Diario Oficial, 22 de septiembre de 2005. 
Decreto 162 del Ministerio de Relaciones Exteriores que Promulga la Convención Interamericana sobre la Protección de los Derechos Humanos de las Personas Mayores. Diario Oficial, 07 de octubre de 2017. Decreto 778 del Ministerio de Relaciones Exteriores que Promulga el Pacto Internacional de Derechos Civiles y Políticos adoptado por la Asamblea General de la Organización de las Naciones Unidas por Resolución ํ⒉200, el 16 de diciembre de 1966 y suscrito por Chile en esa misma fecha. Diario Oficial, 29 de abril de 1989.

Decreto 830 del Ministerio de Relaciones Exteriores que Promulga Convención sobre los Derechos del Niño. Diario Oficial, 27 de septiembre de 1990.

Decreto 873 del Ministerio de Relaciones Exteriores que Aprueba Convención Americana sobre Derechos Humanos, denominada "Pacto de San José de Costa Rica". Diario Oficial, 05 de enero de 1991.

Decreto con Fuerza de Ley $\mathrm{N}^{\circ} 1$ del Ministerio de Justicia que Fija Texto Refundido, Coordinado Y Sistematizado Del Código Civil; De La Ley N4.808, Sobre Registro Civil; De La Ley N¹7.344, Que Autoriza Cambio De Nombres Y Apellidos; De La Ley N016.618, Ley De Menores; De La Ley N¹4.908, Sobre Abandono De Familia Y Pago De Pensiones Alimenticias, Y De La Ley No16.271, De Impuesto A Las Herencias, Asignaciones $Y$ Donaciones. Diario Oficial, 30 de mayo del 2000.

\section{Jurisprudencia citada}

Tyrer v. Reino Unido (1978): Corte Europea de Derechos Humanos 25 abril 1978.

Marckx v. Bélgica (1979): Corte Europea de Derechos Humanos 13 junio 1979.

Fabiola Letelier del Solar y otros contra Ministro del Interior don Sergio Onofre Jarpa Reyes (1983): Tribunal Constitucional 29 octubre 1983 (Requerimiento respecto del artículo 10 de la Constitución Política). Loizidou v. Turquía (1995): Corte Europea de Derechos Humanos 23 marzo 1995. 
Comunidad Indígena Yakye Axa vs. Paraguay (2005): Corte Interamericana de Derechos Humanos 17 junio 2005. Serie C No. 125, par. 125. Masacres de Ituango vs. Colombia (2006): Corte Interamericana de Derechos Humano 1 julio 2006. Serie C No. 148, par. 155; Vid.

Requerimiento de inaplicabilidad por inconstitucionalidad presentado por el Juzgado de Familia de Valdivia, respecto del artículo 206 del Código Civil, en los autos RIT C-966-2009, sobre reconocimiento de paternidad (2009): Tribunal Constitucional 30 agosto 2011.

Requerimiento de inaplicabilidad del juez presidente del Juzgado de Familia de Puadahuel, en la causa RIT C-111-2009, caratulada "Muñoz con Muñoz”, sobre la aplicación del artículo 206 del Código Civil (2009): Tribunal Constitucional 29 septiembre 2009.

Claudio Antonio Agüero Contreras con Servicio de Registro Civil e Identificación (2019): Corte de Apelaciones de San Miguel 04 febrero 2019 (Recurso de Protección) en: Vlex.com, Rol 204-2019.

Rosamel Segundo Soto Vira con Servicio de Registro Civil e Identificación (2019): Corte de Apelaciones de Concepción 11 marzo 2019 (Recurso de Protección) en: Vlex.com, Rol 2359-2019.

Rene Antonio Espinoza Araya con Dirección Regional del Servicio de Registro Civil e Identificación de Arica y Parinacota (2019): Corte de Apelaciones de Arica 13 marzo 2019 (Recurso de Protección) en: Vlex. com, Rol 128-2019.

Rodolfo Sigifredo González Cancino con Servicio de Registro Civil e Identificación (2019): Corte de Apelaciones de Talca 09 abril 2019 (Recurso de Protección) en: Legal Publishing Área Jurídica, cita online: CL/JUR/1985/2019.

Guillermo Cáceres Alvarez y otro con Servicio de Registro Civil e Identificación (2019): Corte de Apelaciones de San Miguel , 15 marzo 2019 (Recurso de Protección) en: Legal Publishing Área Jurídica, cita online: CL/JUR/1370/2019.

Rosa Silva Silva con Servicio de Registro Civil e Identificación (2019): Corte Suprema 10 abril 2019 (Recurso de Protección) en: Legal Publishing Área Jurídica, cita online: CL/JUR/2513/2019.

Marco César Millones Flores con Servicio de Registro Civil e Identifica- 
ción (2019): Corte de Apelaciones de lquique 17 abril 2019 (Recurso de Protección) en: Vlex.com, Rol 106-2019.

Villaroel c/ Servicio de Registro Civil e Identificación (2019): Corte de Apelaciones de Santiago 29 abril 2019 (Recurso de Protección) en: Microjuris, cita online: MJCH_MJJ282272.

Marina Alvarez Molina con Servicio Nacional de Registro Civil e Identificación (2019): Corte de Apelaciones de Santiago 24 mayo 2019 (Recurso de Protección) en: Legal Publishing Área Jurídica, cita online: CL/JUR/2867/2019.

María Transito Vargas Vargas con Registro Civil e Identificación (2019): Corte de Apelaciones de Puerto Montt 05 junio 2019 (Recurso de Protección) en: Vlex.com, Rol 925-2019.

Emelina Maldonado Maldonado con Servicio de Registro Civil e Identificación Metropolitano (2019): Corte de Apelaciones de Santiago 16 junio 2019 (Recurso de Protección) en Legal Publishing Área Jurídica, cita online: CL/JUR/3432/2019.

Elisa Del Carmen Hernandez con Dirección Regional Biobío del Registro Civil e Identificación (2019): Corte de Apelaciones de Concepción 20 junio 2019 (Recurso de Protección) en: Legal Publishing Área Jurídica, cita online: CL/JUR/3764/2019.

Eduardo Germán Ossio Ortiz con Dirección Regional del Servicio de Registro Civil e Identificación de la Región Metropolitana (2019): Corte Suprema 03 julio 2019 (Recurso de Protección) en: Vlex.com, Rol 215-2019.

Jorge Esteban Zamora Reinoso con Servicio de Registro Civil e Identificación (2019): Corte de Apelaciones de Valdivia 12 julio 2019 (Recurso de Protección) en: Vlex.com, Rol 1490-2019.

Cristina Ernilda Herrera Gutiérrez con Servicio de Registro Civil e Identificación (2019): Corte de Apelaciones de Chillán 17 julio 2019 (Recurso de Protección) en: Vlex.com, Rol 813-2019.

Juan Candia Hernández con Servicio de Registro Civil e Identificación (2019): Corte de Apelaciones de Santiago 01 agosto 2019 (Recurso de Protección) en: Legal Publishing Área Jurídica, cita online: CL/ JUR/4391/2019. 
Sonia de Lourdes Núñez Miers con Servicio de Registro Civil e Identificación (2019): Corte Suprema 21 agosto 2019 (Recurso de Protección) en: Vlex.com, Rol 12325-2019.

José Miguel Jofré Rojas con Servicio de Registro Civil e Identificación (2019): Corte Suprema 25 septiembre 2019 (Recurso de Protección) en: Vlex.com, Rol 12101-2019.

Claudio Moya Manriquez con Servicio de Registro Civil e Identificación (2019): Corte Suprema 26 septiembre 2019 (Recurso de Protección) en: Vlex.com, Rol 21326-2019.

Gladys del Carmen Moreno Escobar con Servicio de Registro Civil e Identificación (2019): Corte Suprema 01 octubre 2019 (Recurso de Protección) en: Vlex.com, Rol 14875-2019. 
